\title{
Scalable Lentiviral Vector Production Using Stable HEK293SF Producer Cell Lines
}

\author{
Aziza P. Manceur, Howard Kim,2 Vanja Misic,2 Nadejda Andreev, July Dorion-Thibaudeau, \\ Stéphane Lanthier, Alice Bernier, ${ }^{1}$ Sonia Tremblay, Anne-Marie Gélinas, ${ }^{1}$ Sophie Broussau, \\ Rénald Gilbert, ${ }^{1}$ and Sven Ansorge ${ }^{1}$ \\ ${ }^{1}$ Human Health Therapeutics, National Research Council Canada, Montreal, Canada; ${ }^{2}$ BridGE, Centre for Commercialization of Regenerative Medicine, \\ Toronto, Canada.
}

Lentiviral vectors (LV) represent a key tool for gene and cell therapy applications. The production of these vectors in sufficient quantities for clinical applications remains a hurdle, prompting the field toward developing suspension processes that are conducive to large-scale production. This study describes a LV production strategy using a stable inducible producer cell line. The HEK293 cell line employed grows in suspension, thus offering direct scalability, and produces a green fluorescent protein (GFP)-expressing lentiviral vector in the $10^{6}$ transduction units $(\mathrm{TU}) / \mathrm{mL}$ range without optimization. The stable producer cell line, called clone 92 , was derived by stable transfection from a packaging cell line with a plasmid encoding the transgene GFP. The packaging cell line expresses all the other necessary components to produce LV upon induction with cumate and doxycycline. First, the study demonstrated that LV production using clone 92 is scalable from $20 \mathrm{~mL}$ shake flasks to $3 \mathrm{~L}$ bioreactors. Next, two strategies were developed for high-yield LV production in perfusion mode using acoustic cell filter technology in 1-3 L bioreactors. The first approach uses a basal commercial medium and perfusion mode both pre- and postinduction for increasing cell density and LV recovery. The second approach makes use of a fortified medium formulation to achieve target cell density for induction in batch mode, followed by perfusion mode after induction. Using these perfusion-based strategies, the titer was improved to $3.2 \times 10^{7} \mathrm{TU} / \mathrm{mL}$. As a result, cumulative functional LV titers were increased by up to 15 -fold compared to batch mode, reaching a cumulative total yield of $8 \times 10^{10} \mathrm{TU} / \mathrm{L}$ of bioreactor culture. This approach is easily amenable to largescale production and commercial manufacturing.

Keywords: lentiviral vector, stable producer, HEK293SF, perfusion, bioprocessing

\section{INTRODUCTION}

LENTIVIRAL VECTORS (LV) OFFER a number of valuable properties, including stable gene integration into the host genome, the ability to transfer genetic information into dividing and nondividing cells, and a broad tissue tropism via VSV-G pseudotyping. ${ }^{1}$ They are currently used in clinical trials to treat both rare and more frequent genetic and acquired diseases, ${ }^{2-9}$ as well as in chimeric antigen receptor $\mathrm{T}$ cell cancer therapy. ${ }^{10,11}$
LVs are typically produced using adherent HEK293 cell lines by multi-plasmid transient transfection in serum-containing media. However, this methodology is labor-intensive, plasmid supply-dependent, and not directly scalable. Adherent processes rather need to be scaled out by increasing the available surface for cell attachment and growth. ${ }^{12}$ Transient transfection also results in contaminations of the final product due to excess plasmids ${ }^{13}$ and residual transfection reagent. As

*Correspondence: Dr. Sven Ansorge, National Research Council Canada, Human Health Therapeutics, 6100 Royalmount, Montreal, OC, CAN H4P 2R2. E-mail: sven.ansorge@cnrc-nrc.gc.ca

(C) Aziza P. Manceur et al. 2017; Published by Mary Ann Liebert, Inc. This article is available under the Creative Commons License CCBY-NC (http://creativecommons.org/licenses/by-nc/4.0). This license permits non-commercial use, distribution and reproduction in any medium, provided the original work is properly cited. Permission only needs to be obtained for commercial use and can be done via RightsLink. 
a result, stable $L V$ producer cell lines have been generated. Successful approaches involve the use of an inducible system to circumvent cell death caused by the continuous expression of cytotoxic proteins (Gag, Rev, and VSV-G). ${ }^{14}$ Most reports of stable producer cell lines have described adherent cell lines, ${ }^{5,15,16}$ imposing constraints for scaleup and large-scale production. These challenges have partially been overcome for other viral vectors through the use of highly intensified adherent cultures using single-use fixed-bed bioreactors. ${ }^{17-19}$ In parallel, several academic and industrial laboratories are working on the development of suspension-based production processes, ${ }^{12,20,21}$ which will eventually allow manufacturing of $\mathrm{LV}$ in classical stirred tank bioreactor facilities.

According to recently published reviews, ${ }^{22,23}$ the field is moving toward the use of suspension processes for LV production. Indeed, the use of LV in therapeutic applications requires manufacturing of sufficient amounts of clinical and commercial highquality supply in a reproducible way. Depending on the application and disease, $1-40 \times 10^{9}$ infectious units of vector per patient are needed ${ }^{13}$; this increases the economic pressure and creates the need to develop high-yield production processes. ${ }^{1,22}$

The present study proposes a LV production strategy using a stable inducible producer cell line derived from a packaging cell line that has been previously described ${ }^{14}$ and that grows in suspension in serum-free media (SFM). Induction of expression of the elements necessary to produce LV occurs after the addition of cumate and doxycycline. Because of the notorious low stability of LV, the study opted for the development of a production process in perfusion mode, and two different strategies were evaluated.

\section{MATERIAL AND METHODS Cell culture}

The HEK293SF-LVP-CMVGFPq-92 cell line (abbreviated clone 92) was grown and maintained in SFM4TransFx293 (Hyclone), or in HyCell ${ }^{\mathrm{TM}}$ TransFx-H media (Hyclone), which were both supplemented with $4 \mathrm{mM}$ of L-glutamine in all the experiments described in this study. HyCell ${ }^{\mathrm{TM}}$ TransFx-H was also always completed with $0.1 \%$ poloxamer 188, which is a shear protectant used in high shear stress environments. Cell Boost $5^{\mathrm{TM}}$ (CB5) Supplement (3.5 g/L; Hyclone) is a chemically defined feed and was supplemented only if indicated in the text. Cells were grown in suspension in shake flasks (Corning) with an agitation of 110-120 rpm using orbital shakers (Infors HT), 5\%
$\mathrm{CO}_{2}$ at $37^{\circ} \mathrm{C}$. Cell counts were performed with automated cell counters (Cedex Automated Cell Counter or NucleoCounter ${ }^{\circledR}$ NC-200 ${ }^{\mathrm{TM}}$ ) or using a hemacytometer and erythrosine B. Cells were passaged regularly when reaching densities approaching $2 \times 10^{6}$ cells $/ \mathrm{mL}$.

\section{Generation of stable producer cell line HEK293SF-LVP-CMVGFPq-92 (clone 92) and induction of $L V$ production}

Plasmids used in this study were purified by chromatography using the maxiprep plasmid purification kit (Qiagen) by following the manufacturer's recommendations. The LV packaging cells used to generate HEK293SF-LVP-CMVGFPq-92 have been described previously and were obtained using the One-Shot strategy (i.e., all the LV components were added simultaneously in a single transfection). ${ }^{14}$ To generate clone 92, packaging cells (clone 29-6) grown in LC-SFM medium (Life Technologies) supplemented with $1 \%$ fetal bovine serum (FBS; Hyclone) were co-transfected using Lipofectamine 2000 reagent (Life Technologies) with plasmid pCSIICMV5-GFP previously linearized with StuI and with plasmid pCDNA6-hisA (Life Technologies) encoding the resistance for blasticidin previously linearized with $X h o 1$ at a plasmid mass ratio $(\mu \mathrm{g} / \mu \mathrm{g})$ of $7: 1$. Two days after transfection, $7 \mu \mathrm{g} / \mathrm{mL}$ of blasticidin (InvivoGen) was added to the culture medium, and the cells were grown until a pool of blasticidin-resistant cells was generated (about 3 weeks). The pool was then subcloned by limiting dilution in 96-well plates in medium without blasticidin. Clones were picked and first analyzed for GFP expression. Clones with high levels of GFP expression were expanded and tested for the production of $\mathrm{LV}$; $\mathrm{LV}$ production is initiated by inducing the cells through the addition of $1 \mu \mathrm{g} / \mathrm{mL}$ of doxycycline and $30 \mu \mathrm{g} / \mathrm{mL}$ of cumate. One of the best stable producer clones (clone 92) was adapted to grow in serum-free conditions in SFM4 Transfx-293 medium (Hyclone), supplemented with $4 \mathrm{mM}$ of glutamine. A research cell bank was made in the same medium supplemented with $10 \%$ dimethyl sulfoxide (Sigma-Aldrich).

\section{Stability study of clone 92}

Clone 92 was thawed in SFM4TransFx-293 and cultivated in suspension culture in $125 \mathrm{~mL}$ shaker flasks with $20 \mathrm{~mL}$ of culture volume. At 2, 6, and 10 weeks after thawing, cells were induced at a concentration of $1.0 \times 10^{6}$ cell $\mathrm{s} / \mathrm{mL}$ for the production of LV. At $48 \mathrm{~h}$ post induction, the medium was clarified by centrifugation, and the supernatant containing the LV was supplemented with $1 \%$ FBS (as cryoprotectant) and then frozen at $-80^{\circ} \mathrm{C}$. The 
amount of LV in the supernatant was titrated simultaneously by gene transfer assay (GTA; see section "GTA for lentiviral quantification" below).

\section{LV production in shake flasks}

In the first set of shake flask experiments, cells were seeded at $0.2 \times 10^{6}$ cells $/ \mathrm{mL}$ in SFM4TransFx293 medium. Once the cells reached a cell density of $1-1.5 \times 10^{6}$ cells $/ \mathrm{mL}$, they were split into $50 \mathrm{~mL}$ aliquots in $250 \mathrm{~mL}$ shake flasks. Daily medium replacement (DMR) was performed for five consecutive days until induction by pelleting the cells by centrifugation ( $300 \mathrm{~g}, 5 \mathrm{~min})$ and resuspending them in different ratios $(0-100 \%)$ of fresh versus spent medium. Cell counts and viability were determined with a Cedex Automated Cell Counter after treating the cells for $30 \mathrm{~min}$ with Accumax ${ }^{\mathrm{TM}}$ (Sigma-Aldrich) to reduce cell aggregation.

In the second set of experiments, cells were inoculated at a cell density of $0.3 \times 10^{6}$ cells $/ \mathrm{mL}$ into $100 \mathrm{~mL}$ of complete $\mathrm{HyCell}^{\mathrm{TM}}$ TransFx-H media supplemented with $3.5 \mathrm{~g} / \mathrm{L} \mathrm{CB} 5$ and batch cultured in a $500 \mathrm{~mL}$ shake flask. When cell density reached $\geq 5 \mathrm{E} 6$ cells $/ \mathrm{mL}$, the cell suspension was split into $20 \mathrm{~mL}$ aliquots in $125 \mathrm{~mL}$ shake flasks, and cells were induced ( $1 \mu \mathrm{g} / \mathrm{mL}$ of doxycycline and $30 \mu \mathrm{g} / \mathrm{mL}$ of cumate). Starting at $24 \mathrm{~h}$ after induction and every $24 \mathrm{~h}$ thereafter, cells were subjected to DMR at $50 \%$ with medium either supplemented with $3.5 \mathrm{~g} / \mathrm{L}$ CB5 or not. The collected medium was filtered through a $0.45 \mu \mathrm{m}$ filter, and LV content was titrated by GTA. Daily cell counts and viability measurements were performed using the NucleoCounter ${ }^{\circledR}$ NC-200 ${ }^{\mathrm{TM}}$.

\section{Bioreactor LV productions}

The bioreactor setup used for the four batch runs and perfusion run \#1 was identical to the one used in a previous study ${ }^{12}$; similar conditions have been described earlier in detail. ${ }^{24}$ In brief, a Chemap 3.5 L type SG bioreactor vessel (working volume $2.7 \mathrm{~L}$ ) was equipped with probes to measure and control different parameters (temperature of $37^{\circ} \mathrm{C}$; $\mathrm{pH}$ 7.05-7.1; dissolved oxygen [DO] 40\%; agitation $80 \mathrm{rpm})$. In perfusion mode, cells were retained in the bioreactor using a $10 \mathrm{~L}$ acoustic filter (AppliSens) operated in backflush mode (full recycling of cell suspension into bioreactor at each backflush) with an interval of $30 \mathrm{~min}$ and a run/stop ratio of $55 / 5 \mathrm{~s}$ (Fig. 4). Cultures were grown up to $\sim 1-$ $1.5 \times 10^{6}$ cells $/ \mathrm{mL}$ in batch mode. Perfusion was started at 0.5 volume of medium per reactor volume per day (VVD), and increased to up to 1 VVD after induction. The culture was induced after reaching the targeted cell density $\left(5 \times 10^{6}\right.$ cells $\left./ \mathrm{mL}\right)$ in perfusion mode.

For perfusion \#2-4, cells were inoculated at cell densities ranging from 0.25 to $0.35 \times 10^{6}$ cells $/ \mathrm{mL}$ into $1 \mathrm{~L}$ of complete $\mathrm{HyCell}^{\mathrm{TM}}$ TransFx-H media (Hyclone) supplemented with $3.5 \mathrm{~g} / \mathrm{L}$ CB5, and cultured in the BioFlo ${ }^{\circledR} 3201 \mathrm{~L}$ stirred tank reactor in batch mode $\left(37^{\circ} \mathrm{C} ; \mathrm{pH} 7.15\right.$; DO $\left.40 \% ; 80 \mathrm{rpm}\right)$. Cells were induced at $\geq 5 \times 10^{6}$ cells $/ \mathrm{mL}$. After induction, perfusion mode (1 VVD) was started with fresh medium containing inducers for 5-7 days. The miniBioSep (Applikon ${ }^{\circledR}$ ) was used for cell retention ( $1 \mathrm{~W}$ power setting) during perfusion. Cell counts and viability measurements were performed using the NucleoCounter ${ }^{\circledR}$ NC-200 ${ }^{\mathrm{TM}}$ after daily sampling from the bioreactor.

In all perfusion runs, harvests were collected, and the LV-containing supernatant was kept on ice or at $4^{\circ} \mathrm{C}$ until clarification (once daily) and subsequently stored at $-80^{\circ} \mathrm{C}$ until quantification using the GTA assay. As two different bioreactor scales were used in this study, the total cumulative $\mathrm{LV}$ yield is normalized per liter of bioreactor culture (TU/L) to facilitate direct comparison.

\section{GTA for lentiviral quantification}

Functional viral titer (GTA titer) was determined using a flow cytometry-based GTA, as described previously with slight modifications. ${ }^{12,21}$ In brief, HEK293A or 293T cells were cultured in Dulbecco's modified Eagle's medium (DMEM) containing $5 \% \mathrm{FBS}$ and $2 \mathrm{mM}$ of L-glutamine. The cells were seeded at a density of $1 \mathrm{E} 05$ cells/well of a 24-well plate $5 \mathrm{~h}$ before transduction with LV. Prior to transduction, LV samples were serially diluted in DMEM supplemented with $8 \mu \mathrm{g} / \mathrm{mL}$ of polybrene and incubated at $37^{\circ} \mathrm{C}$ for $30 \mathrm{~min}$. Transduction was performed by removing culture medium, adding $200 \mu \mathrm{L}$ of diluted $\mathrm{LV}$ to cells, and incubating over night at $37^{\circ} \mathrm{C}$. Next day, $800 \mu \mathrm{L}$ of culture medium was added to each well, and cells were incubated for an additional $48 \mathrm{~h}$ prior to flow cytometry to quantify GFP expressing cells. Therefore, GFP was measured 3 days post transduction. Note that the GFP signal measured is truly due to transgene expression and not to the presence of episomes, since a similar signal was measured 10 days post transduction in a control experiment (Supplementary Fig. S1; Supplementary Data are available online at www.liebertpub.com/hgtb). The titer $(\mathrm{TU} / \mathrm{mL})$ is determined using the formula [(\% of GFP positive cells $/ 100) \times($ number of cells transduced $) \times($ dilution factor $) \times(1 \mathrm{~mL} /$ volume transduced)]. An in-house LV standard was used in all measurements to minimize inter-assay variability. 


\section{RESULTS}

\section{Generation and stability of a stable producer cell line (clone 92)}

A packaging cell line that contains all the necessary components to produce $L V$, except for the LV genomic RNA, has been described previously. ${ }^{14}$ Briefly, all the LV components (Gag/Pol, Rev, and VSV-G) were added simultaneously through a single transfection event to generate a packaging cell line named PacLV. In the packaging cells, transcription of Rev and the envelope protein (VSV-G) is under the control of the tetracycline and cumate switches, which means that addition of doxycycline and cumate in the culture medium is required to induce the production of LV (Fig. 1A). $\mathrm{Gag} / \mathrm{Pol}$ is under the control of a CMV promoter. Even though the expression of Gag/Pol is constitutive and not directly controlled by the switches, its expression depends on the presence of REV because of a REV responsive element (RRE). A cell line (known as producer) that contains all the elements necessary to produce LV, including the genomic RNA, was then constructed. For ease of titration, a decision was made to construct producer for LV expressing GFP regulated by the strong constitutive CMV promoter. This was done by co-transfecting the packaging cells with the transfer vector pCSII-CMV5-GFPq, which also contains a RRE. Details about the plasmid construction have been previously reported. ${ }^{14}$ The producer cell line selected was named clone 92 . To confirm that the production of LV from clone 92 was stable, the cells were cultivated for 10 weeks in shake flasks, and the production of LV was monitored at different time points after induction. LV titers $>3.0 \times 10^{6} \mathrm{TU} / \mathrm{mL}$ were maintained throughout this period of time, indicating that clone 92 is stable (Fig. 1B).

\section{LV production in bioreactors operated in batch mode}

In order to evaluate the performance of clone 92 in stirred tank bioreactors, four batch cultivations were performed at the $3.5 \mathrm{~L}$ scale (Fig. 2) in SFM4TransFx293 media, our starting basal medium for this cell line. The viability profile after induction was showing a reproducible decline, reaching $70-80 \%$ at 3 days post induction (dpi; Fig. 2A). Functional LV titer production kinetics exhibit a reproducible peak at $3 \mathrm{dpi}$, with an average titer of $6 \times 10^{6} \mathrm{TU} / \mathrm{mL}$ (Fig. 2B). Production was found to be directly scalable from shake flasks to bioreactors in batch mode, with comparable production profiles (Fig. 2C). The total LV yield per liter of culture was of $6 \times 10^{9}$ TU on average (Fig. 2D), with a specific production of $4.4 \mathrm{TU} /$ cell.

\section{LV production in small scale}

In order to address the low stability of LV, the plan was to use continuous harvesting in perfusion mode to recover produced LV rapidly. As a model, two strategies were explored in shake flasks. First, experiments were performed to determine the effect of DMR during the cell growth phase and to
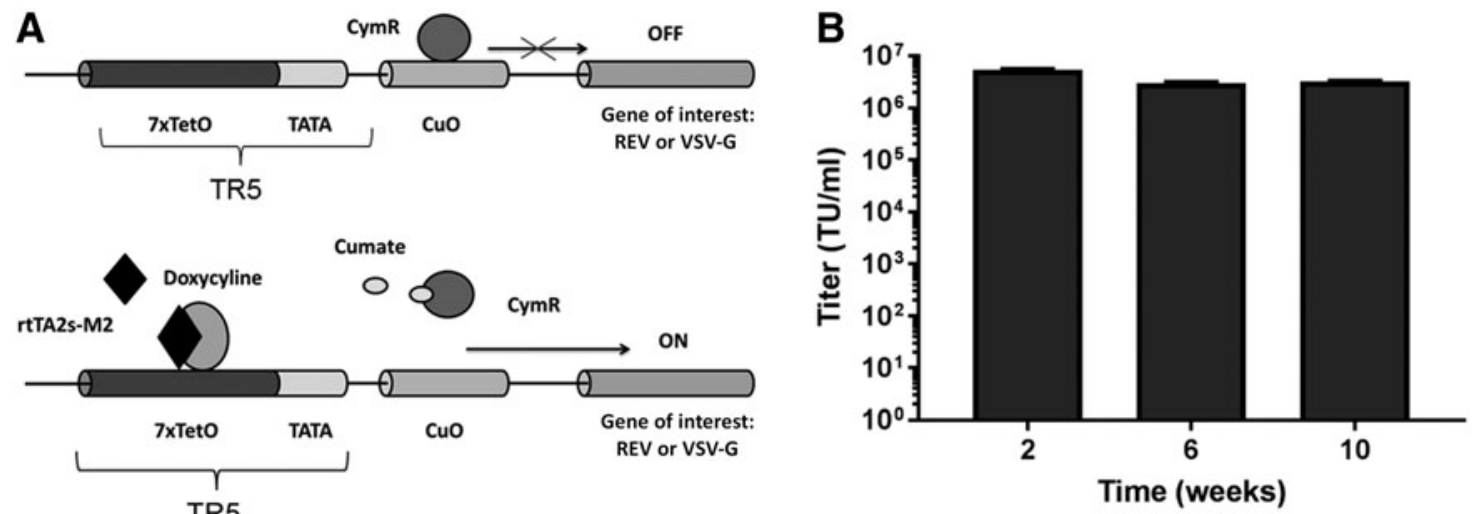

Figure 1. Schematic of the cumate-inducible system and stability of clone 92. (A) In the packaging cells and thus also clone 92 , transcription of Rev and the envelope protein (VSV-G) is under the control of the tetracycline and cumate switches. Addition of doxycycline and cumate in the culture medium is required to induce the production of LV. Cumate prevents binding of the cumate repressor (CymR) to the cumate operator (Cu0). Doxycycline promotes binding of the reverse tetracycline transactivator (rtTA2s-M2) to the tetracycline promoter (TR5). (B) To test the stability of clone 92, the cells were maintained in suspension culture without selective pressure for 10 weeks. After 2,6 , and 10 weeks of culture, a portion of the cells were induced at a concentration of $1.0 \times 10^{6} \mathrm{cells} / \mathrm{mL}$ by addition of doxycycline and cumate. The amount of LVs produced at $48 \mathrm{~h}$ post induction was analyzed by gene transfer assay (GTA) in triplicate (error bars show the standard deviation). 


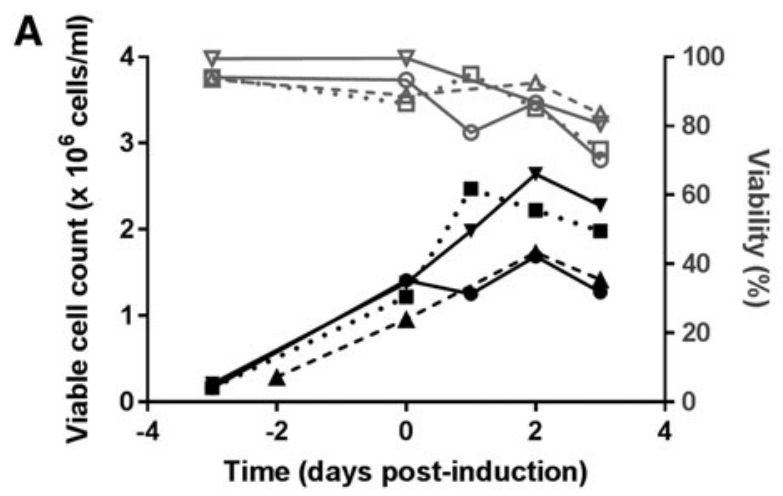

Batch 1 - Batch $2-$ - Batch $3 \rightarrow$ Batch 4

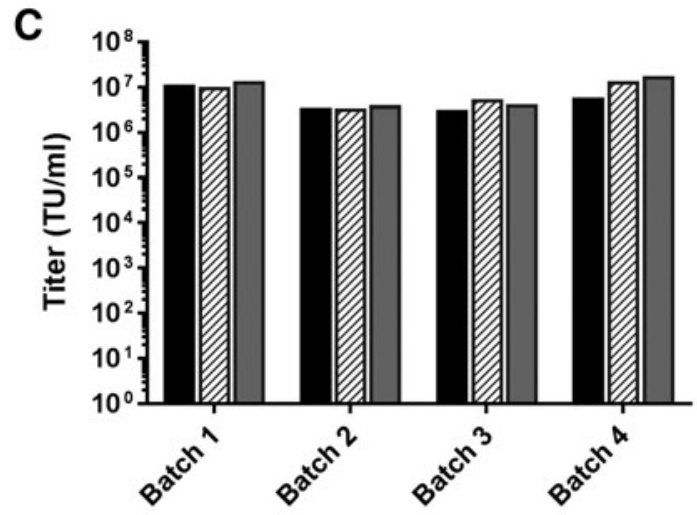

Bioreactor $\square$ External control $\square$ Internal control

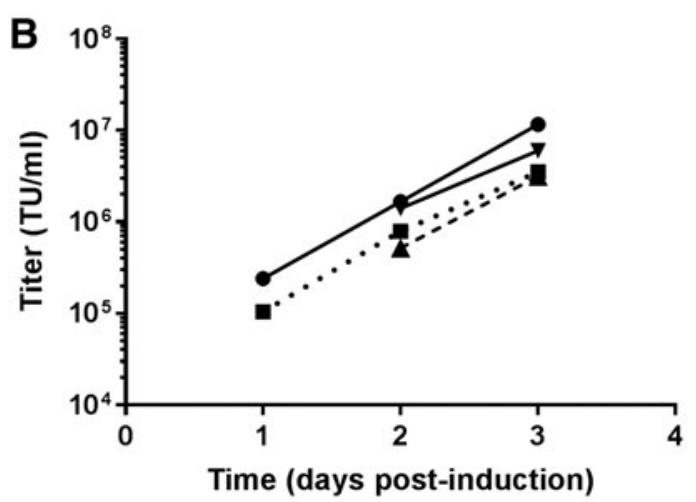

Batch $1 \cdot$ Batch $2-$ - B. Batch $3 \rightarrow$ Batch 4

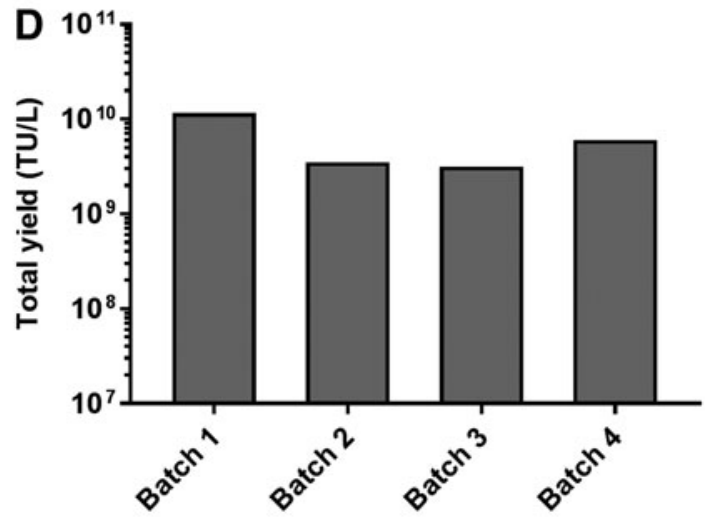

Figure 2. Results obtained in $3 \mathrm{~L}$ bioreactor runs operated in batch mode. (A) Viable cell count (black line) and viability (gray line) measured in four independent bioreactor runs (batches 1-4) operated in batch mode using SFM4TransFx293 medium. (B) Functional titer kinetics for four batch runs up to 3 days post induction. (C) Functional LV titers at $3 \mathrm{dpi}$ for four independent batch productions and related shake flask controls. The internal control was obtained by sampling an aliquot from the bioreactor shortly after induction. This aliquot was then transferred into and kept in a shake flask during the LV production phase. The external control was performed in parallel in shake flask throughout the experiment during both the growth phase and LV production phase. (D) Total functional titer produced per $1 \mathrm{~L}$ batch culture for four batch runs.

test the impact of higher cell density at induction on production yield. Cells were centrifuged once daily, and $0-100 \%$ of the spent medium was replaced by fresh SFM4Transfx293 medium between $-3 \mathrm{dpi}$ and $0 \mathrm{dpi}$. Results show that the growth phase could be extended through the daily addition of increasing amounts of fresh medium; a cell density of $>8 \times 10^{6}$ cells $/ \mathrm{mL}$ was reached at $0 \mathrm{dpi}$ through complete daily medium replacement over 4 days (Fig. 3A), which is three times more than the batch control. Following induction, LV was quantified at $3 \mathrm{dpi}$. Titer was significantly increased by media replacement going from $1.0 \times 10^{6} \mathrm{TU} / \mathrm{mL}$ without DMR to $3.35 \times 10^{7} \mathrm{TU} / \mathrm{mL}$ when $75-100 \%$ of the spent medium was replaced with fresh medium (Fig. 3B). A better specific production was measured with $75 \%$ DMR compared to $100 \%$ DMR. This indicates that an optimal cell density at induction for LV production under the conditions used is the one obtained with $75 \% \mathrm{DMR}$, which is approximately $5.5 \times 10^{6}$ cell $\mathrm{s} / \mathrm{mL}$.

Therefore, a cell density at induction of $5 \times 10^{6}$ cells $/ \mathrm{mL}$ was targeted in the second set of smallscale experiments. A hybrid system combining the use of a fortified medium during the cell growth phase and DMR during the production phase was tested. A new medium formulation that does not contain hydrolysates and promises a lower lot-tolot variability (HyCell ${ }^{\mathrm{TM}}$ TransFx-H) was chosen. In our hands, the LV titers were similar between SFM4TransFx293 and HyCell ${ }^{\mathrm{TM}}$ TransFx-H when induction took place at $5 \times 10^{6}$ cells $/ \mathrm{mL}$ after daily medium replacement of $75 \%$ (Supplementary Table S1).

In order to support growth to high cell density in batch mode, HyCell ${ }^{\mathrm{TM}}$ TransFx-H was supplemented with Cell Boost 5 (CB5), and cells were grown to $5 \times 10^{6}$ cells $/ \mathrm{mL}$ until induction; $50 \%$ daily 

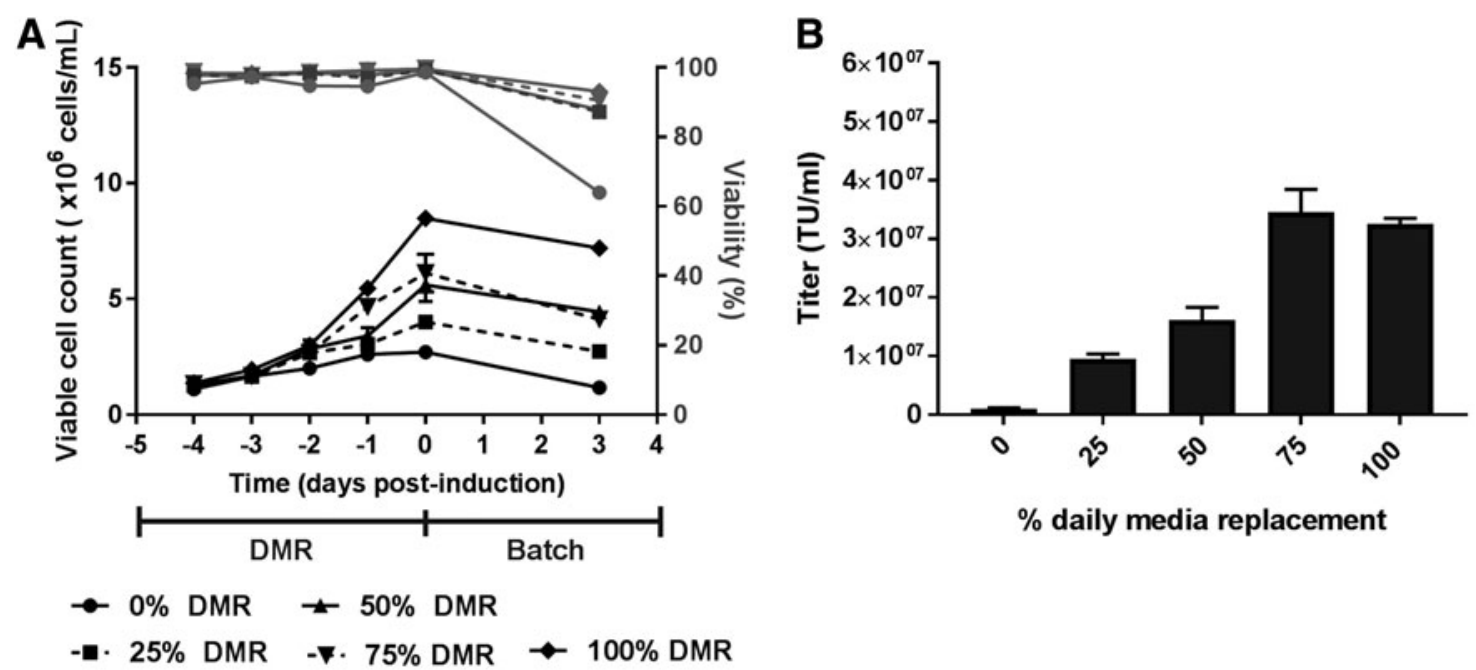

$\%$ daily media replacement
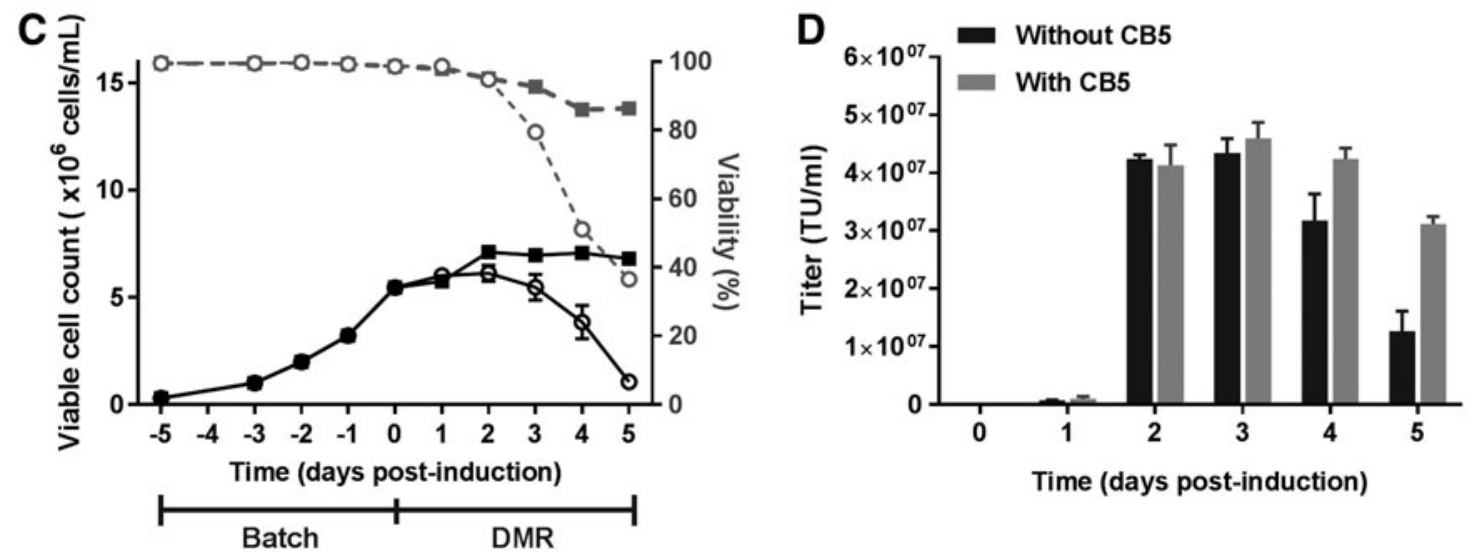

Figure 3. Results obtained in shake flasks. (A) Viable cell count (black line) and viability (gray line) between -4 dpi and 3 dpi upon daily media replacement (DMR) at $0-100 \%$ in SFM4TransFx293 medium. Medium replacement took place on $-3 \mathrm{dpi},-2 \mathrm{dpi},-1 \mathrm{dpi}$, and $0 \mathrm{dpi}$ in duplicate shake flasks. (B) LV titer was measured by GTA at $3 \mathrm{dpi}$ for samples in duplicate shown in panel (A) (error bars show the standard deviation). (C) Viable cell count and viability of cells in HyCell ${ }^{\mathrm{TM}}$ TransFx-H media supplemented with $3.5 \mathrm{~g} / \mathrm{L}$ of Cell Boost $5^{\mathrm{TM}}$ Supplement (CB5; squares) or without CB5 (circles). For each LV producer cell suspension, DMR was performed at $50 \%$ with fresh media, either supplemented with CB5 or not (two independent shake flasks for both conditions) every $24 \mathrm{~h}$ following induction. (D) The functional titer (TU/mL) was assayed for each of the harvests shown in panel (C) for both conditions by GTA (error bars show the standard deviation).

media replacement took place during the production phase with or without CB5 addition (Fig. 3C). Similar functional LV titers were obtained at 50\% DMR with or without CB5 from $1 \mathrm{dpi}$ to $3 \mathrm{dpi}$. However, supplementing with CB5 improved the daily titer at $4 \mathrm{dpi}$ and $5 \mathrm{dpi}$ (Fig. 3D). Taken together, these data suggest that expanding cells in a fortified medium (HyCell ${ }^{\mathrm{TM}}$ TransFx-H with CB5) results in cell densities similar to what is obtained in perfusion mode with simplified bioreactor operation until induction. In addition, adding CB5 during the production phase prolongs the production phase, presumably by improving cell viability.

\section{Improved production in perfusion mode}

Based on the results obtained in shake flasks, parameters were selected for bioreactor productions performed in perfusion mode. A schematic of the setup used to operate in perfusion mode is shown in Fig. 4. The first run (Perfusion 1) was performed using SFM4TransFx293 medium for growth and production in a $3.5 \mathrm{~L}$ stirred tank bioreactor and is used as a reference. Perfusion was started at 0.5 VVD and increased to up to 1 VVD after induction.

In an effort to simplify the process, three additional runs (Perfusion 2-4) were operated using a hybrid mode similar to what was performed in shake flasks; cells were expanded in $1 \mathrm{~L}$ of $\mathrm{HyCell}^{\mathrm{TM}}$ TransFx-H media supplemented with CB5 in batch mode. Cultures were induced at densities $\geq 5 \times 10^{6}$ cells/mL, and perfusion mode was started (1 VVD) with fresh medium containing CB5 and inducers. The cell density and viability of Perfusion 1 is significantly different from Perfusion 2-4 after 


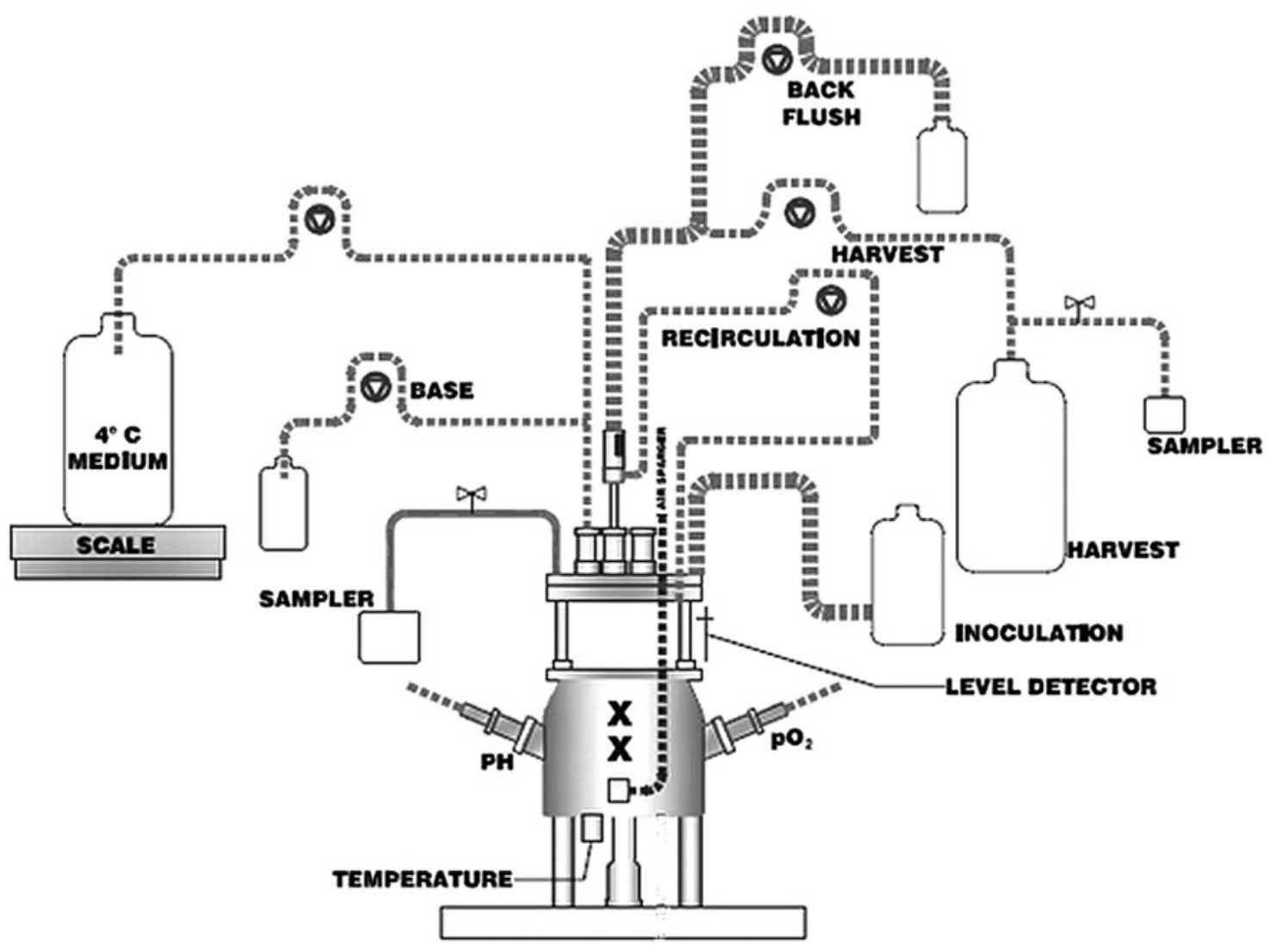

Figure 4. Schematic showing the setup used in perfusion mode. Cells are transferred into the bioreactor vessel using the inoculation bottle at $0.25-0.35 E 06$ cells $/ \mathrm{mL}$. Cell-free daily harvests and samplings are performed using the harvest bottle and the associated sampler under sterile conditions (cells are retained using an acoustic filter and are recirculated into the bioreactor while the supernatant is harvested). The sampler on the left-hand side is used to sample cells daily to measure cell density and viability. Medium is kept at $4^{\circ} \mathrm{C}$ and pumped into the vessel so that $0.5-1$ volume of medium per reactor volume vessel is added over $24 \mathrm{~h}$; the exact volume of media added is further monitored using a scale and a level detector. Oxygen $\left(\mathrm{pO}_{2}\right)$, temperature, and $\mathrm{pH}$ are monitored with sterilizable probes. The pH is kept between 7.05 and 7.1 through the addition of $\mathrm{CO}_{2}$ via the surface or the addition of a base $\left(\mathrm{NaHCO}_{3}\right)$. Peristaltic pumps are also shown on the schematic (reversed triangle in a circle).

induction (Fig. 5A and B); the viability dropped quickly after induction, similarly to what was observed in cultures without CB5 supplementation (Figs. 2A and $3 \mathrm{~A}$ and $\mathrm{C}$ ), and the run was stopped at 5 dpi when the viability reached $25 \%$. In contrast, the viable cell density of Perfusion runs 2-4 showed no growth arrest and increased up to $17 \times 10^{6}$ cells $/ \mathrm{mL}$ after induction; viability remained $>80 \%$ until harvest (Fig. 5A and B). The peak in titer $\left(2-3 \times 10^{7} \mathrm{TU} / \mathrm{mL}\right)$ was observed at $3 \mathrm{dpi}$ for Perfusion 1, whereas it was at $4 \mathrm{dpi}$ for Perfusion 2-4 (Fig. 5C). Cumulative titers of the four perfusion runs are in a similar range of $5-8 \times 10^{10} \mathrm{TU} / \mathrm{L}$, with the cumulative titer of Perfusion 1 being highest (Fig. 5D). The titers measured in the bioreactor versus the harvest vessel are comparable (Supplementary Fig. S2).

Compared to the batch cultures, the average peak titer measured in the harvest for the four perfusion runs $\left(2.2 \times 10^{7} \mathrm{TU} / \mathrm{mL}\right)$ is nearly fourfold higher than the one obtained in batch mode $\left(6 \times 10^{6}\right.$ TU/mL; Fig. 2B). Furthermore, on average, 11 times more total LV (up to $8 \times 10^{10} \mathrm{TU} / \mathrm{L}$ ) is obtained in perfusion mode compared to batch mode because of the daily harvests (Fig. 5B). The viable cell density at time of induction was between 1 and $1.5 \times 10^{6}$ cells $/ \mathrm{mL}$ in batch, whereas it was $5.4 \times 10^{6}$ cells $/ \mathrm{mL}$ in perfusion. The specific production was also improved in perfusion with an average of 11.5 TU/cell compared to $4.4 \mathrm{TU} /$ cell in batch mode.

\section{DISCUSSION}

Using a stable producer cell line (clone 92), two strategies were developed for high yield LV production in perfusion mode. The first approach uses the basal medium SFM4TransFx293 and perfusion mode for both increasing cell density and $L V$ recovery (Figs. 3A and B and 5A and B). The second approach made use of a new medium formulation (HyCell $^{\mathrm{TM}}$ 

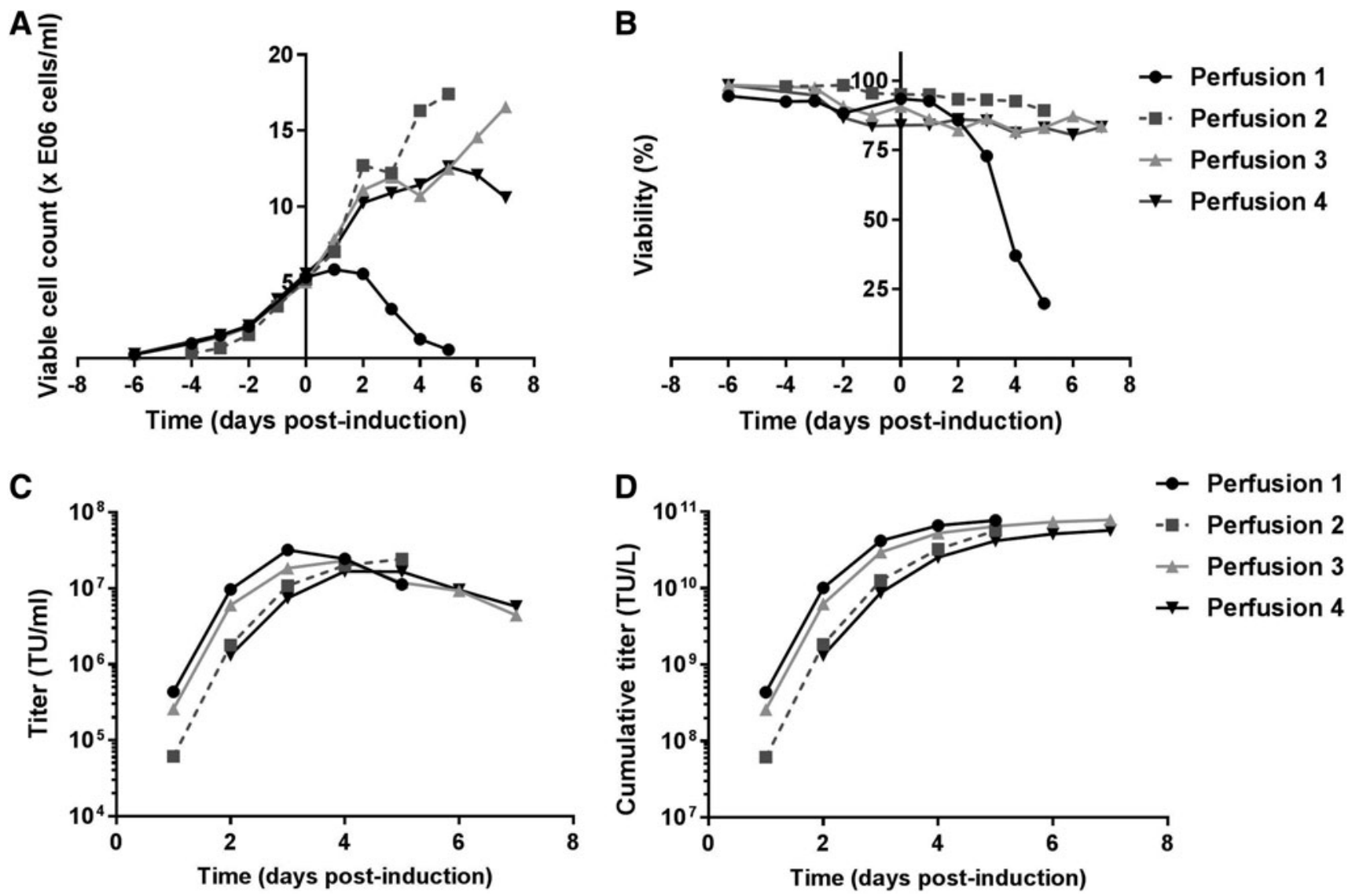

Figure 5. Cell viability and titers measured in four independent perfusion cultures. (A) Viable cell counts (VCC) and (B) cell viability prior to and after induction of virus production at 1-3.5 L scale. (C) Functional LV titer (TU/mL) was assayed from each of the daily harvests (perfusion filtrate collected on ice) from the four independent runs using the GTA assay. (D) The cumulative titers were calculated for $1 \mathrm{~L}$ harvests for all the runs.

TransFx-H) in combination with medium fortification through CB5 addition: this approach might be simpler to operate, since the perfusion mode is only started after induction (Figs. 3C and D and 5C and D). Overall, it was possible to increase the cumulative yield of LV to up to 15 -fold compared to batch mode. Although it is expected that the absolute LV titers of $8 \times 10^{10} \mathrm{TU} / \mathrm{L}$ are transgene dependent, it is hypothesized that the yield improvements of $>1 \log$ compared to batch mode will be transferable to other transgenes.

A few adherent stable producer cell lines have been described with $L V$ titers in the range of $1 \times 10^{6}-1.5 \times 10^{8} .{ }^{25-27}$ However, adherent cell lines present significant limitations for large-scale productions. In the strategy employed here, the mother cell line (HEK293SF-3F6) used to generate the packaging cell line and subsequently the stable producer was already adapted to suspension and serum-free conditions. ${ }^{28}$ A key element for the successful generation of clone 92 was the use of a double switch system; two inducers are required to initiate the synthesis of LV, which offers a tight control on the production of LV cytotoxic elements. Early attempts using only one switch were not successful (results not shown). The producer cell line reported here is grown in suspension, but further process optimization could be pursued. For example, CB5 addition seemed to extend the window of high $\mathrm{LV}$ titers $\left(>10^{7} \mathrm{TU} / \mathrm{mL}\right)$ to beyond 4-5 dpi and also slowed down the decline in culture viability while maintaining cell growth after induction. CB5 contains several nutrients that support cell viability but may have some components (e.g., growth factors) that may be counterproductive to vector output. Indeed, comparing CB5 addition to its absence during induction in shake flasks, LV titers are at comparable levels but much lower on a per-cell basis with CB5 (Fig. 3C and D). It is envisioned that this system could be manipulated to balance LV production (a cytotoxic process) and cell maintenance to develop a continuous LV production model. In contrast, production in the basal medium SFM4TransFx293 without supplementation led to a faster release of LV until 3 dpi (Fig. 4C and D). A combination of CB5 supplementation 
during the growth phase and removal of CB5 during the production phase could lead to a further increase in production yields at earlier time points. An extensive metabolite analysis and further CB5 titration could also be beneficial and support induction at higher cell densities.

The recovery after purification and downstream processing will also affect the final functional titers. ${ }^{29,30}$ The authors are currently investigating the use of column/membrane chromatography to decrease the amount of impurities in the final product, as published by other teams. ${ }^{21,31,32}$ Purification should also aim at removing the two inducers used in this study. Cumate is known for being non-cytotoxic, ${ }^{33}$ but doxycycline is an antibiotic of the tetracycline class. Therefore, this could be an issue for people with tetracycline allergies if traces are present in the final product.

In conclusion, to the best of the authors' knowledge, this study is the first to describe process development and improvement efforts for a stable LV producer suspension HEK293 cell line. The process described was reproducible and robust from small scale to 1-3 L bioreactor scale. Two strategies for improvement of the cumulative LV yield were tested. Both of these employed acoustic cell filter technology to operate bioreactor cultures in perfusion mode. Overall, an increase in cumulative LV titer (TU per L of bioreactor culture) of $>1$ log was achieved. This means that it was possible to produce up to $8 \times 10^{10} \mathrm{TU} / \mathrm{L}$ bioreactor volume in perfusion mode. It is expected that the developed production process will be easily amenable to largescale production and commercial manufacturing.

\section{ACKNOWLEDGMENTS}

The authors would like to acknowledge the contribution of Julia Transfiguracion, Adam McLeod, Nick Timmins, Aaron Dulgar-Tulloch, Mélanie Simoneau, and Nazila Nazemi-Moghaddam to this work. Work performed at CCRM was co-funded by FedDev Ontario (Advanced Manufacturing Fund) and GE Healthcare.

\section{AUTHOR DISCLOSURE}

No competing financial interests exist

\section{REFERENCES}

1. Segura MM, Mangion M, Gaillet B, et al. New developments in lentiviral vector design, production and purification. Expert Opin Biol Ther 2013; 13:987-1011.

2. Blits $B$, Petry $H$. Perspective on the road toward gene therapy for Parkinson's disease. Front Neuroanat 2016;10:128.

3. Brown BD, Cantore A, Annoni A, et al. A microRNA-regulated lentiviral vector mediates stable correction of hemophilia B mice. Blood 2007:110:4144-4152.

4. Cavazzana M, Six E, Lagresle-Peyrou $C$, et al Gene therapy for X-linked severe combined immunodeficiency: where do we stand? Hum Gene Ther 2016;27:108-116.

5. Greene MR, Lockey T, Mehta PK, et al. Transduction of human CD34+ repopulating cells with a self-inactivating lentiviral vector for SCID-X1 produced at clinical scale by a stable cell line. Hum Gene Ther Methods 2012;23:297-308.

6. Malik P, Arumugam PI, Yee JK, et al. Successful correction of the human Cooley's anemia betathalassemia major phenotype using a lentiviral vector flanked by the chicken hypersensitive site 4 chromatin insulator. Ann N Y Acad Sci 2005;1054 238-249.

7. May C, Rivella S, Callegari J, et al. Therapeutic haemoglobin synthesis in beta-thalassaemic mice expressing lentivirus-encoded human beta-globin. Nature 2000;406:82-86
8. Pawliuk R, Westerman KA, Fabry ME, et al. Correction of sickle cell disease in transgenic mouse models by gene therapy. Science 2001;294:23682371.

9. Ribeil JA, Hacein-Bey-Abina S, Payen E, et al. Gene therapy in a patient with sickle cell disease. N Engl J Med 2017;376:848-855

10. Levine BL, Miskin J, Wonnacott K, et al. Global manufacturing of CAR $T$ cell therapy. Mol Ther Methods Clin Dev 2017:4:92-101.

11. Sadelain M, Brentjens R, Riviere I. The basic principles of chimeric antigen receptor design. Cancer Discov 2013;3:388-398.

12. Ansorge S, Lanthier S, Transfiguracion J, et al. Development of a scalable process for high-yield lentiviral vector production by transient transfection of HEK293 suspension cultures. J Gene Med 2009;11:868-876.

13. Sanber KS, Knight SB, Stephen SL, et al. Construction of stable packaging cell lines for clinical lentiviral vector production. Sci Rep 2015:5:9021.

14. Broussau S, Jabbour N, Lachapelle G, et al. Inducible packaging cells for large-scale production of lentiviral vectors in serum-free suspension culture. Mol Ther 2008;16:500-507.

15. Sinn PL, Sauter SL, McCray PB Jr. Gene therapy progress and prospects: development of improved lentiviral and retroviral vectors-design, biosafety, and production. Gene Ther 2005;12:10891098
16. Stornaiuolo A, Piovani BM, Bossi S, et al. RD2MolPack-Chim3, a packaging cell line for stable production of lentiviral vectors for anti-HIV gene therapy. Hum Gene Ther Methods 2013;24:228240.

17. Lesch HP, Heikkila KM, Lipponen EM, et al. Process development of adenoviral vector production in fixed bed bioreactor: from bench to commercial scale. Hum Gene Ther 2015:26:560-571.

18. Powers AD, Piras BA, Clark RK, et al. Development and optimization of AAV hFIX particles by transient transfection in an iCELLis ${ }^{\circledR}$ fixed-bed bioreactor. Hum Gene Ther Methods 2016;27: 112-121

19. Wang X, Olszewska M, Qu J, et al. Large-scale clinical-grade retroviral vector production in a fixed-bed bioreactor. J Immunother 2015;38:127135

20. Gutierrez-Granados S, Cervera L, Segura Mde L, et al. Optimized production of HIV-1 virus-like particles by transient transfection in CAP-T cells. Appl Microbiol Biotechnol 2016;100:3935-3947.

21. Segura MM, Garnier A, Durocher $Y$, et al. Production of lentiviral vectors by large-scale transient transfection of suspension cultures and affinity chromatography purification. Biotechnol Bioeng 2007;98:789-799.

22. McCarron A, Donnelley M, McIntyre C, et al Challenges of up-scaling lentivirus production and processing. J Biotechnol 2016;240:23-30. 
23. Merten OW, Hebben M, Bovolenta C. Production of lentiviral vectors. Mol Ther Methods Clin Dev 2016;3:16017.

24. Henry $\mathrm{O}$, Dormond $\mathrm{E}$, Perrier $\mathrm{M}$, et al. Insights into adenoviral vector production kinetics in acoustic filter-based perfusion cultures. Biotechnol Bioeng 2004:86:765-774.

25. Lee CL, Chou M, Dai B, et al. Construction of stable producer cells to make high-titer lentiviral vectors for dendritic cell-based vaccination. Biotechnol Bioeng 2012;109:1551-1560.

26. Wielgosz MM, Kim YS, Carney GG, et al. Generation of a lentiviral vector producer cell clone for human Wiskott-Aldrich syndrome gene therapy. Mol Ther Methods Clin Dev 2015; 2:14063.
27. Xu K, Ma H, McCown TJ, et al. Generation of a stable cell line producing high-titer self-inactivating lentiviral vectors. Mol Ther 2001;3:97-104.

28. Cote J, Garnier A, Massie B, et al. Serum-free production of recombinant proteins and adenoviral vectors by 293 SF-3F6 cells. Biotechnol Bioeng 1998:59:567-575.

29. Bandeira $V$, Peixoto $C$, Rodrigues $A F$, et al. Downstream processing of lentiviral vectors: releasing bottlenecks. Hum Gene Ther Methods 2012;23:255-263.

30. Ausubel LJ, Hall C, Sharma A, et al. Production of CGMP-grade lentiviral vectors. Bioprocess Int 2012;10:32-43.

31. Merten OW, Charrier S, Laroudie N, et al. Large-scale manufacture and characterization of a lentiviral vector produced for clinical ex vivo gene therapy application. Hum Gene Ther 2011;22:343-356.

32. Kutner RH, Puthli S, Marino MP, et al. Simplified production and concentration of HIV-1-based lentiviral vectors using HYPERFlask vessels and anion exchange membrane chromatography. BMC Biotechnol 2009;9:1-7.

33. Poulain A, Perret $S$, Malenfant $F$, et al. Rapid protein production from stable $\mathrm{CHO}$ cell pools using plasmid vector and the cumate gene-switch. J Biotechnol 2017;255:16-27.

Received for publication May 16, 2017;

accepted after revision August 21, 2017.

Published online: August 21, 2017. 